\title{
Influence of mealtime habits on the risk of weight gain and obesity in Mexican adults
}

\author{
Libia Darina Dosamantes-Carrasco 1,2 , Pablo Méndez-Hernández ${ }^{3,4, *}$, \\ Yvonne N Flores ${ }^{2,5}$, Carole Siani ${ }^{6,7}$, Edgar Denova-Gutiérrez ${ }^{8}$, Katia Gallegos-Carrillo ${ }^{2}$, \\ Paula Ramírez ${ }^{2}$, Berenice Rivera-Paredez ${ }^{2}$, Eduardo Salazar-Martínez ${ }^{9}$ \\ and Jorge Salmerón 2,9 \\ 'École Interdisciplinaire Sciences-Santé, Université Claude Bernard Lyon 1, University of Lyon, Lyon, France: \\ ${ }^{2}$ Unidad de Investigación Epidemiológica y en Servicios de Salud, Instituto Mexicano del Seguro Social, \\ Cuernavaca, México: ${ }^{3}$ Facultad de Ciencias de la Salud, Universidad Autónoma de Tlaxcala, Calle Ciencias de la \\ Salud sur No. 11, Guardia, Zacatelco, CP 90750, Tlaxcala, México: ${ }^{4}$ Departamento de Calidad y Educación en \\ Salud, Secretaría de Salud de Tlaxcala, Ignacio Picazo Norte \# 25, Colonia Centro, CP 90800, Tlaxcala, México: \\ ${ }^{5}$ UCLA Department of Health, School of Public Health and Jonsson Comprehensive Cancer, Los Angeles, CA, USA: \\ ${ }^{6}$ Aix Marseille University, INSERM, IRD, SESSTIM UMRS912, Marseille, France: ${ }^{7}$ University of Lyon, University \\ Claude Bernard Lyon 1, Lyon, France: ${ }^{8}$ Unidad de Investigación en Epidemiología Clínica, Hospital Infantil de \\ México 'Federico Gómez', Ciudad de México, México: ${ }^{9}$ Centro de Investigación en Salud Poblacional, Instituto \\ Nacional de Salud Pública, Cuernavaca, México
}

Submitted 5 January 2016: Final revision received 15 June 2016: Accepted 11 July 2016: First published online 26 September 2016

\begin{abstract}
Objective: To prospectively examine the extent to which mealtime habits influences the risk of weight gain and obesity in Mexican adults.

Design: We performed a prospective cohort study. The Mealtime Habits Quality (MHQ) scale was used for assessing participants' MHQ; the outcomes of interest were gain $\geq 5 \%$ of body weight, developing overweight/obesity and abdominal obesity, after 7 years of follow-up. In order to estimate the independent effect of MHQ on anthropometric indicators, generalized linear models were computed to obtain adjusted relative risks (95\% CI).

Setting: The state of Morelos, Mexico.

Subjects: Mexican adults ( $n$ 837) aged $18-70$ years participating in a cohort study. Results: Compared with participants classified in the higher MHQ category, individuals in the middle and lower MHQ groups had a $4.1(2.5,6.7)$ and $6.2(3.9,9.7)$ fold greater risk of gain $\geq 5 \%$ of body weight, respectively; $6 \cdot 6(2 \cdot 8,15 \cdot 5)$ and $8 \cdot 6(3 \cdot 7,19 \cdot 8)$ fold greater risk of becoming overweight/obese, respectively; and $3 \cdot 8(2 \cdot 0,7 \cdot 3)$ and $5 \cdot 3(2 \cdot 8,9 \cdot 8)$ fold greater risk of developing abdominal obesity, respectively.

Conclusions: This study provides evidence about the influence of a set of mealtime habits on obesity indicators, showing that greater adherence to unadvisable mealtime habits increases the risk of developing unhealthy anthropometric indicators. Since the meal is one of the most important sources of food intake, and consequently weight status, the MHQ scale can be a useful population tool to predict weight gain and obesity.
\end{abstract}

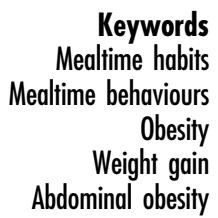

The social scientific community suggests that the global epidemic of obesity cannot be explained by focusing solely on food products and amount of food intake, showing that what people do while eating can predict food consumption and weight status ${ }^{(1)}$. For instance, distractions during eating meals, such as watching television (TV), reading, working, listening to a detective story, listening to music or playing video games, can

increase how much food is consumed. These behaviours have also been associated with higher intakes of fat, fast foods and soft drinks, but lower intakes of fruit and vegetables, resulting in a greater likelihood of becoming overweight $^{(2-10)}$. Other sources of distractions are social interactions, which inhibit consumption monitoring and make people more vulnerable to mindless eating, increasing energy intake and weight gain risk $^{(1,11,12)}$. 
In fact, researchers have shown that non food-related environmental stimuli, such as TV and auditory stimuli, are able to provoke a significant increase of meal size and energy intake ${ }^{(2)}$.

Some other behaviours that influence food intake and body weight are related with a lack of sufficient time to eat: rushing meals has been associated with greater soft drink, fast food and fat consumption, as well as with a lower intake of healthful foods ${ }^{(13)}$; skipping breakfast has been related with higher rates of obesity and elevated fasting blood insulin and cholesterol levels ${ }^{(14,15)}$; and eating out of home has been associated with a diet high in energy and $\mathrm{fat}^{(16)}$, and lower vegetable and fruit consumption ${ }^{(17)}$, which leads to a higher risk of obesity ${ }^{(18)}$.

The eating environment, which includes the ambience atmospherics, social interactions and distractions, may lead to decreased consumption monitoring, resulting in an increase in food consumption ${ }^{(1)}$. The potential stimulatory influence of different environmental factors can make people more vulnerable to mindless eating. For instance, the sensory stimulation of being with family, friends or colleagues provokes eating, which influences meal size and increases energy intake regardless of hunger or need status at the start of the meal ${ }^{(2,19,20)}$.

The Mealtime Habits Quality (MHQ) scale was previously assessed in a cross-sectional study in Mexican adults participating in the Health Workers Cohort Study (HWCS) and computes the contribution of eight advisable and unadvisable mealtime items. As expected, lower MHQ score was related to higher rates of overweight and abdominal obesity, unhealthy dietary patterns, lower intakes of fruits and vegetables, and lower levels of leisure-time physical activity $^{(21)}$. In the present research we attempt to highlight how a set of behaviours that people do at the mealtimes can influence some key health anthropometric indicators. Thus, in the present study we sought to estimate the risk of gaining body weight, becoming overweight/obese and developing abdominal obesity after 7 years of follow-up, according to Mexican adults' mealtime habits quality.

\section{Materials and methods}

\section{Study population}

This is a prospective cohort study composed of 1725 active and retired health workers aged 18-70 years at baseline, who participated in two data collection periods of the HWCS: baseline assessment at 2004-2006 and follow-up assessment at 2010-2012. The HWCS is an ongoing cohort study to assess relationships between lifestyle and health, being conducted at the Instituto Mexicano del Seguro Social (Mexican Social Security Institute) and the Instituto Nacional de Salud Pública (National Institute of Public Health), both located in Cuernavaca, Morelos state, Mexico ${ }^{(22)}$. We excluded those participants who did not complete all questions related to mealtime habits at both data collection periods ( $n$ 653) and those with health conditions that affect weight or mealtime habits in either assessment, such as diabetes or taking diabetes medications ( $n$ 144), determination of plasma glucose $\geq 125 \mathrm{mg} / \mathrm{dl}$ ( $n$ 34), cancer ( $n$ 28), kidney failure ( $n$ 10), CVD ( $n$ 10) and pregnancy ( $n$ 9); thus, the study population consisted of 837 participants (209 men and 628 women). This research was performed in accordance with the Helsinki declaration on human studies ${ }^{(23)}$; each person signed an approved informed consent form prior to entering the study. The Ethics Committee of the Instituto Mexicano del Seguro Social from the state of Morelos approved the study protocol.

\section{Assessment of mealtime habits quality}

Originally, the MHQ scale was constructed using eight items in binary response format and was validated among 7472 Mexican health workers who were participating in the cohort study ${ }^{(21)}$. In order to examine a wider range of possible mealtime behaviours ${ }^{(24)}$, the MHQ scale was transformed to a multiple-choice response format in the follow-up assessment (Table 1).

First, mealtime items were categorized into two groups, advisable and unadvisable for good health, based on published studies that report how certain mealtime circumstances can influence diet and body weight ${ }^{(1,5,8,21)}$. Then, the following six specific meal situations were examined in the present study.

1. Availability of time to eat was measured using four items from the baseline assessment: 'I take my time to finish my meal', 'I rush my meals to avoid exceeding the available time to eat', 'I eat in huge mouthfuls' and 'I eat slowly'. In order to avoid duplication, these four items were replaced with two questions at the follow-up evaluation: 'How fast do you eat your meals?', since this question has been previously associated with lack of time to eat and obesity $^{(13,16)}$, and additionally we included the question 'Do you skip any meal a day?', since skipping meals has been related with obesity ${ }^{(14,15,25)}$.

2. Distraction from eating has been related to increased food intake and obesity ${ }^{(3-9)}$. This mealtime situation was measured using two items from the baseline assessment: 'I'm distracted: I talk, watch TV or read' and 'I take advantage of mealtimes to accomplish work activities'. These two items were combined into one question for the follow-up evaluation: 'Are you distracted while eating, either by watching TV, working, reading, chatting or solving everyday problems?'

3. Food selection, which is closely related to energy intake and $\mathrm{BMI}^{(4)}$, was measured at baseline with the item 'I choose what I eat'. However, in order to be more specific about the type and amount of food selected by participants, this question was divided into two questions for the follow-up assessment: 'Do you choose the type of food you eat, thinking about your 
Table 1 Factor loadings of the mealtime habit items, comparing binary responses at baseline and multiple-choice responses at follow-up assessment; Health Workers Cohort Study, Morelos, Mexico

\begin{tabular}{|c|c|c|c|c|c|c|c|}
\hline \multicolumn{3}{|c|}{ MHQ scale: items with binary response (2004-2006 baseline assessment) } & \multicolumn{5}{|c|}{ MHQ scale: items with multiple-choice responses (2010-2012 follow-up assessment) } \\
\hline \multirow[b]{2}{*}{ Mealtime situations } & \multirow{2}{*}{$\begin{array}{l}\text { Question: When you eat, } \\
\text { generally, what do you do? }\end{array}$} & \multirow{2}{*}{$\begin{array}{l}\text { Factor loading of binary } \\
\text { responses: yes or no }\end{array}$} & \multirow[b]{2}{*}{ Question } & \multicolumn{4}{|c|}{ Factor loading of multiple-choice responses } \\
\hline & & & & Never & Almost never & Almost always & Always \\
\hline \multirow[t]{3}{*}{ Availability of time to eat } & $\begin{array}{l}\text { I take my time to finish my } \\
\text { meal }\end{array}$ & 0.72 & $\begin{array}{l}\text { Do you take the time to finish } \\
\text { your meal? }\end{array}$ & -0.72 & -0.42 & $-0 \cdot 10$ & 0.35 \\
\hline & $\begin{array}{l}\text { I rush my meals to avoid } \\
\text { exceeding the available } \\
\text { time to eat }\end{array}$ & $-0 \cdot 71$ & Did you skip any meal a day? & 0.41 & -0.07 & -0.47 & -0.83 \\
\hline & $\begin{array}{l}\text { I eat in huge mouthfuls } \\
\text { I eat slowly }\end{array}$ & $\begin{array}{r}-0.68 \\
0.53\end{array}$ & $\begin{array}{l}\text { How fast do you eat your } \\
\text { meals? }\end{array}$ & $\begin{array}{l}\text { Very fast } \\
-0.71\end{array}$ & $\begin{array}{c}\text { Fast } \\
-0.27\end{array}$ & $\begin{array}{l}\text { Slowly } \\
-0.10\end{array}$ & $\begin{array}{c}\text { Very slowly } \\
0.49\end{array}$ \\
\hline Distractions from eating & $\begin{array}{l}\text { I'm distracted (I talk, watch } \\
\text { TV or read) } \\
\text { I take advantage of } \\
\text { mealtimes to accomplish } \\
\text { work activities }\end{array}$ & $\begin{array}{l}-0.23 \\
-0.37\end{array}$ & $\begin{array}{l}\text { Are you distracted when you } \\
\text { are eating, either by } \\
\text { watching TV, working, } \\
\text { reading, chatting or solving } \\
\text { everyday problems? }\end{array}$ & $\begin{array}{r}\text { Never } \\
0.25\end{array}$ & $\begin{array}{c}\text { Almost never } \\
0.04\end{array}$ & $\begin{array}{c}\text { Almost always } \\
-0.05\end{array}$ & $\begin{array}{l}\text { Always } \\
-0.21\end{array}$ \\
\hline \multirow[t]{2}{*}{ Environmental factors } & $\begin{array}{l}\text { This mealtime situation } \\
\text { was not evaluated at the } \\
\text { baseline assessment }\end{array}$ & & $\begin{array}{l}\text { Do you eat together with } \\
\text { friends, family or } \\
\text { colleagues? }\end{array}$ & $\begin{array}{l}\text { Never } \\
-0.36\end{array}$ & $\begin{array}{l}\text { Almost never } \\
-0.21\end{array}$ & $\begin{array}{l}\text { Almost always } \\
-0.06\end{array}$ & $\begin{array}{c}\text { Always } \\
0.12\end{array}$ \\
\hline & & & $\begin{array}{l}\text { Weekly, how many times do } \\
\text { you eat the principal meal at } \\
\text { home? }\end{array}$ & $\begin{array}{r}0-1 \text { time } \\
-0.55\end{array}$ & $\begin{array}{l}2-3 \text { times } \\
-0.29\end{array}$ & $\begin{array}{l}4-5 \text { times } \\
-0.09\end{array}$ & $\begin{array}{c}6-7 \text { times } \\
0.23\end{array}$ \\
\hline $\begin{array}{l}\text { Familial and cultural } \\
\text { customs of consumption }\end{array}$ & $\begin{array}{l}\text { I eat all my food, without } \\
\text { leaving anything on the } \\
\text { plate }\end{array}$ & -0.26 & $\begin{array}{l}\text { Do you eat all your food, } \\
\text { without leaving anything on } \\
\text { the plate? }\end{array}$ & $\begin{array}{r}\text { Never } \\
0.13\end{array}$ & $\begin{array}{l}\text { Almost never } \\
-0.06\end{array}$ & $\begin{array}{c}\text { Almost always } \\
0.00\end{array}$ & $\begin{array}{c}\text { Always } \\
0.12\end{array}$ \\
\hline \multirow[t]{2}{*}{ Enjoy eating } & $\begin{array}{l}\text { This mealtime situation } \\
\text { was not evaluated at the }\end{array}$ & & Do you enjoy eating? & $\begin{array}{l}\text { I never } \\
\text { enjoy }\end{array}$ & $\begin{array}{l}\text { Almost never I } \\
\text { enjoy }\end{array}$ & $\begin{array}{l}\text { Almost always I } \\
\text { enjoy }\end{array}$ & $\begin{array}{l}\text { Always I } \\
\text { enjoy }\end{array}$ \\
\hline & baseline assessment & & & -1.09 & -0.63 & -0.13 & 0.38 \\
\hline \multirow[t]{2}{*}{ Food selection } & I choose what I eat & 0.24 & $\begin{array}{l}\text { Do you choose the type of food } \\
\text { you eat thinking about your } \\
\text { health? }\end{array}$ & $\begin{array}{l}\text { Never } \\
-0.88\end{array}$ & $\begin{array}{l}\text { Almost never } \\
-0.48\end{array}$ & $\begin{array}{l}\text { Almost always } \\
-0.06\end{array}$ & $\begin{array}{c}\text { Always } \\
0.45\end{array}$ \\
\hline & & & $\begin{array}{l}\text { Do you choose the amount of } \\
\text { food you eat? }\end{array}$ & -0.80 & -0.47 & $-0 \cdot 10$ & 0.39 \\
\hline Explained variance (\%) & 26 & & Explained variance (\%) & & & & \\
\hline $\begin{array}{l}\text { Median score (range) } \\
\text { Cronbach's a coefficient }\end{array}$ & $\begin{aligned} 6.2(1.3 \\
0.8\end{aligned}$ & $-8 \cdot 7)$ & $\begin{array}{l}\text { Median score (range) } \\
\text { Cronbach's } a \text { coefficient }\end{array}$ & & 3.7 & $\begin{array}{l}5-6 \cdot 7) \\
0\end{array}$ & \\
\hline
\end{tabular}

TV, television. 
health?' and 'Do you choose the amount of food that you eat?'

4. Familial and cultural eating habits have been related to increased food intake ${ }^{(1,20)}$. This was assessed at baseline with the item 'I eat all my food, without leaving anything on the plate'; while at the follow-up it was changed to 'Do you eat all your food, without leaving anything on the plate?'

The two following mealtime situations, which have been shown to influence food intake, were incorporated at the follow-up assessment.

5. Environmental and social context of eating, which was measured with the items 'Do you eat together with friends, family or colleges?' ${ }^{(1,20)}$ and 'How many times a week do you eat the main meal at home? ${ }^{(13-16)}$.

6. Enjoy eating, which was assessed with the question 'Do you enjoy eating?', because greater pleasure with food has been associated with fewer food anxieties, less dieting behaviours and lower BMI ${ }^{(26)}$ (Table 1).

Next, in order to evaluate the equivalence between the two versions of the MHQ instrument, we used parallel-form reliability ${ }^{(27)}$. Both formats of the MHQ questionnaire were tested in a cross-sectional study about lifestyle and stated preferences regarding health promotion programmes to prevent chronic diseases among 425 employees of a Mexican public university ${ }^{(28,29)}$. Thus, respondents answered both formats of the MHQ questionnaire at the same time: the binary items were placed at the beginning of the questionnaire and the multiple-choice items at the end.

In order to compare if the multiple-choice format of the MHQ questionnaire was compatible with the MHQ in binary format, we transformed the multiple-choice format into binary responses. Participants were categorized into 'yes' when they answered 'almost always' or 'always' in the multiplechoice version, and were categorized into 'no' when they responded 'almost never' or 'never'. Participants who selected the option 'sometimes' in the Likert format were eliminated from the analysis, because typically the Likert scale midpoints indicate ambivalence or indifference and they are not indicative of a tendency ${ }^{(27)}$. The binary format and the dichotomized Likert scale were very similar in the following ways: (i) the percentage of participants who answered positively or negatively - in both instruments was very similar ( $P \geq 0.726$ in all items); (ii) the overall mean scores and SD of the MHQ were very similar for both formats, a mean of 5.13 for the binary and 5.12 for the dichotomizedLikert format $(P=0.997)$; and (iii) the overall reliability coefficient between two scales was 0.946 (see online supplementary material, Supplemental Table 1).

\section{Assessment of dietary patterns}

Dietary patterns and energy intake were obtained using a semi-quantitative FFQ validated in a Mexican population ${ }^{(30)}$. This questionnaire included data on the consumption frequency of 116 food items commonly consumed over the past year, ranging from never to $\geq 6$ times/d.

We used the three major dietary patterns that were previously identified in a cross-sectional study of 9467 Mexican adults participating in the $\mathrm{HWCS}^{(31)}$ to assess changes in adherence to certain dietary patterns that have been associated with anthropometric indicators and adiposity ${ }^{(21,22,31)}$. Briefly, in both assessments, food items were classified into twenty-eight food groups based on similarity in nutrients, lipid content profile, sugar content, proportion of dietary fibre and commonly consumed foods. Three dietary patterns were derived: the prudent pattern is typified by greater intakes of processed vegetable juices, potatoes, fresh fruits, fresh vegetables and legumes, and a lower intake of pastries; the Western pattern is characterized by higher intakes of pastries, refined cereals, corn tortillas and soft drinks, and lower intakes of whole cereals, seafood and full-fat dairy products; and the high animal protein/fat dietary pattern is typified by greater intakes of red meat, processed meat, margarine and eggs, and lower intakes of fruits and wholegrain cereals. The factor score for each dietary pattern was constructed by summing the standardized percentages of energy intake of food groups, weighted by their factor loading. We created panel data for longitudinal analysis by obtaining a personallevel data set of the participants' adherence to the three dietary patterns, for both stages of the study. Then, individuals were classified into tertiles, with the highest tertile reflecting greater adherence to each dietary pattern.

\section{Anthropometric assessment}

At the baseline and follow-up assessment, weight was measured with a previously calibrated electronic TANITA scale (model BC-533; Tokyo, Japan) on participants who had fasted overnight and were wearing minimal clothing. Height was measured using a conventional stadiometer while the participants were standing barefoot, with their shoulders in a normal position. Waist circumference was measured to the nearest $0.1 \mathrm{~cm}$ at the high point of the iliac crest at the end of normal expiration, with a steel measuring tape. In order to analyse waist circumference, we considered the categories proposed by the National Cholesterol Education Program Adult Treatment Panel III: normal waist circumference was defined if women presented $<88 \mathrm{~cm}$ and men $<102 \mathrm{~cm}$; and abdominal obesity was defined by waist circumference $\geq 88 \mathrm{~cm}$ for women and $\geq 102 \mathrm{~cm}$ for men $^{(32)}$. All measurement procedures were performed by nurses trained to use standardized procedures. BMI $\left(\mathrm{kg} / \mathrm{m}^{2}\right)$ was calculated as the ratio of weight to height squared. In order to analyse BMI, we used the categories proposed by the WHO: normal weight, $B M I=18.5-24.9 \mathrm{~kg} / \mathrm{m}^{2} ; \quad$ overweight, $\mathrm{BMI}=25 \cdot 0-29 \cdot 9 \mathrm{~kg} / \mathrm{m}^{2}$; obesity, BMI $\geq 30 \cdot 0 \mathrm{~kg} / \mathrm{m}^{2(33)}$.

The anthropometric outcomes of interest after 7 years of follow-up were: gaining $\geq 5 \%$ of body weight, since this cut-off point represents an increased risk for developing 
type 2 diabetes ${ }^{(34)}$; becoming overweight or obese ${ }^{(35)}$; and developing abdominal obesity, because this is a more accurate predictor of all-cause mortality ${ }^{(36)}$, cardiac and/or metabolic disease risk than excess weight gain evaluated by $\mathrm{BMI}^{(37)}$.

\section{Depression}

Depressive symptoms were assessed using a Spanishlanguage depression scale, a version of a twenty-item questionnaire created by the Center for Epidemiologic Studies ${ }^{(38)}$. We defined probable clinical depression using the mean plus one SD as a cut-off point; this criterion has been previously used to define depressive symptoms in a Mexican population ${ }^{(22)}$. To determine which participants had depressive symptoms at baseline and follow-up assessments, we generated a continuous scale from 0 to 60 points and a score of $\geq 16$ suggested probable clinical depression $^{(22,38)}$

\section{Physical activity and smoking}

Leisure-time physical activity was assessed using a validated physical activity questionnaire ${ }^{(39)}$, validated in Spanish ${ }^{(40)}$, and adapted for the Mexican urban population of the HWCS ${ }^{(41)}$. We defined two categories of physical activity level: $<30 \mathrm{~min} / \mathrm{d}$ and $\geq 30 \mathrm{~min} / \mathrm{d}$, based on the minimum amount of time of physical activity recommended for health in Mexican adults ${ }^{(42)}$. Smoking status was assessed using the categorization proposed by the WHO: current, past and never ${ }^{(43)}$.

\section{Demographic data}

We categorized marital status as never married, married, divorced or widowed. Educational attainment was categorized into elementary and secondary education, high school education, and bachelor's degree or higher.

\section{Statistical analysis}

Factor analysis at baseline assessment (2004-2006)

In the baseline evaluation the MHQ scale was constructed with binary response items, obtaining information about structured mealtimes without taking snacks into consideration. Participants were asked: 'When you eat, generally, what do you do?', indicating their mealtime habits with either 'yes' or 'no'. Then, an exploratory factor analysis was performed to uncover underlying factors and factor loadings of eight binary items. The factor solution of mealtime habit items was composed of only one factor, with an explained variance of $26.6 \%$; advisable mealtime habits were correlated positively and unadvisable mealtime habits were correlated negatively. The MHQ scale was constructed by summing the contribution of each item weighted by its factor loading. Since the indicator had negative values, the number 5 was added to the total summarized score to obtain a positive scale. Each participant received an individual score representing the quality of his/her mealtime habits, with higher scores corresponding to better quality. The MHQ scale had a median of 6.2 points, with a range of 1.3 to 8.7 (SD 1.3); internal consistency with Cronbach's $\alpha$ test was $0 \cdot 84^{(21)}$ (Table 1).

Factor analysis at follow-up assessment (2010-2012) In the follow-up assessment, the MHQ scale was constructed with multiple-choice responses. Thus an exploratory factor analysis for polytomous responses was performed on ten items using the principal component method. The factor solution was composed of only one factor with an explained variance of $26.7 \%$. Eight items had a factor loading of greater than $0 \cdot 30$, and advisable mealtime habits were correlated positively and unadvisable mealtime habits were correlated negatively. Just as in the baseline assessment of the MHQ, the scale had negative values, so the number 5 was added to the total summarized score in order to obtain a positive scale. The mealtime habits score in this assessment had a median of 3.7 points, ranging from -0.54 to 6.71 (SD 1.19); internal consistency with Cronbach's $\alpha$ test was $0 \cdot 60$ (Table 1 ).

\section{Data analyses}

Differences in sociodemographic, lifestyle and anthropometric characteristics were examined at baseline and follow-up, testing differences between two means using the $t$ test for paired samples and assessing differences between two proportions using the McNemar test (Table 2).

The MHQ scale was constructed by summing the factor loadings of each mealtime habits item and participants were assigned an individual MHQ score at baseline and another at the follow-up assessment. Next, panel data were created for obtaining a personal-level data set, in order to control for unobserved heterogeneity ${ }^{(44)}$, and individuals were classified into tertiles (the highest tertile indicates a more advisable MHQ), with one MHQ status for baseline and another for follow-up, so we could relate MHQ status with each participant's corresponding weight gain and obesity status at baseline or follow-up. Then, in order to demonstrate if there were any differences in sociodemographic, anthropometric, lifestyle characteristics and dietary patterns across the MHQ tertiles, Cochran's $Q$ tests were performed to assess the differences between three proportions for nominal variables across MHQ tertiles and the Fisher test was performed to determine any difference between the means of the continuous variables across the MHQ tertiles (Tables 3 and 4).

Then we analysed the three events of interest; some participants were eliminated from the analysis: (i) to estimate the risk of gaining $\geq 5 \%$ of body weight, 130 participants who lost $\geq 5 \%$ of their body weight were excluded, leaving 707 participants; (ii) to estimate the risk of becoming overweight/obese, only those participants with a normal BMI at baseline were included ( $n$ 358); and (iii) to evaluate the risk for becoming abdominally obese, only 
Table 2 Demographic, anthropometric and lifestyle characteristics of the Mexican adult participants ( $n$ 837; men $24.9 \%$ and women $75.1 \%)$ at baseline and follow-up evaluations; Health Workers Cohort Study, Morelos, Mexico

\begin{tabular}{|c|c|c|c|}
\hline & $\begin{array}{l}\text { Baseline } \\
\text { 2004-2006 }\end{array}$ & $\begin{array}{l}\text { Follow-up } \\
2010-2012\end{array}$ & $\begin{array}{c}P \\
\text { value* }\end{array}$ \\
\hline Age (years), mean & $44 \cdot 5$ & $51 \cdot 6$ & 0.000 \\
\hline SD & $12 \cdot 2$ & $12 \cdot 3$ & \\
\hline \multicolumn{4}{|l|}{ Marital status } \\
\hline Never married (\%) & 0.6 & 0.2 & 0.250 \\
\hline $\begin{array}{l}\text { Married or living in free } \\
\text { union (\%) }\end{array}$ & $64 \cdot 8$ & $60 \cdot 6$ & 0.080 \\
\hline $\begin{array}{l}\text { Divorced, widowed or } \\
\text { separated }(\%)\end{array}$ & $34 \cdot 6$ & $39 \cdot 2$ & 0.050 \\
\hline \multicolumn{4}{|l|}{ Education } \\
\hline $\begin{array}{l}\text { Elementary and } \\
\text { secondary education (\%) }\end{array}$ & $27 \cdot 9$ & $26 \cdot 3$ & 0.060 \\
\hline High school (\%) & 23.9 & $25 \cdot 0$ & 0.070 \\
\hline $\begin{array}{l}\text { Bachelor's degree or } \\
\text { higher (\%) }\end{array}$ & $48 \cdot 2$ & $48 \cdot 7$ & 0.840 \\
\hline $\begin{array}{l}\text { BMI }\left(\mathrm{kg} / \mathrm{m}^{2}\right) \text {, mean } \\
\text { SD }\end{array}$ & $\begin{array}{r}25.5 \\
4.4\end{array}$ & $\begin{array}{r}26.5 \\
4.4\end{array}$ & 0.830 \\
\hline Normal weight† (\%) & $42 \cdot 8$ & $35 \cdot 8$ & 0.002 \\
\hline Overweight $†(\%)$ & $40 \cdot 8$ & $43 \cdot 5$ & 0.199 \\
\hline Obesity† (\%) & $16 \cdot 4$ & $20 \cdot 7$ & 0.024 \\
\hline \multicolumn{4}{|l|}{ Waist circumference (cm) } \\
\hline Men, mean & $94 \cdot 2$ & $98 \cdot 0$ & 0.000 \\
\hline SD & 9.9 & $10 \cdot 7$ & \\
\hline Women, mean & 88.9 & $90 \cdot 0$ & 0.00 \\
\hline SD & 11.8 & $10 \cdot 9$ & \\
\hline \multicolumn{4}{|l|}{ Abdominal obesity $\ddagger$} \\
\hline Men (\%) & $21 \cdot 3$ & 31.5 & 0.019 \\
\hline Women (\%) & $50 \cdot 0$ & 63.5 & 0.000 \\
\hline \multicolumn{3}{|l|}{ score, mean } & 0.000 \\
\hline $\mathrm{SD}$ & $1 \cdot 1$ & $1 \cdot 1$ & \\
\hline Lower MHQ category (\%) & $19 \cdot 3$ & $48 \cdot 6$ & 0.000 \\
\hline Middle MHQ category (\%) & $26 \cdot 6$ & $38 \cdot 7$ & 0.000 \\
\hline Higher MHQ category (\%) & 54.0 & $12 \cdot 7$ & 0.000 \\
\hline Energy intake $(\mathrm{kJ} / \mathrm{d})$, mean & 8916 & 7891 & 0.000 \\
\hline SD & 3686 & 3251 & \\
\hline Energy intake $(\mathrm{kcal} / \mathrm{d})$, mean & 2131 & 1886 & 0.000 \\
\hline SD & 881 & 777 & \\
\hline $\begin{array}{l}\text { Recreational physical } \\
\text { activity, } \geq 30 \mathrm{~min} / \mathrm{d}(\%)\end{array}$ & $37 \cdot 1$ & 31.6 & 0.020 \\
\hline Smoking status, smoker (\%) & $15 \cdot 8$ & $11 \cdot 3$ & 0.009 \\
\hline Depression§ (\%) & $21 \cdot 0$ & $20 \cdot 0$ & 0.600 \\
\hline
\end{tabular}

${ }^{\star} P$ value calculated using the McNemar test for differences in two proportions, and the $t$ test for paired samples for differences in two means, between baseline and follow-up assessments. Proportions and means were adjusted for age and sex. $P \leq 0.05$ was considered to be significant.

$\dagger$ Normal weight, $\mathrm{BMI}=18.5-24.9 \mathrm{~kg} / \mathrm{m}^{2}$; overweight, $\mathrm{BMI}=25.0-29.9 \mathrm{~kg} / \mathrm{m}^{2}$; obesity, $\mathrm{BMI} \geq 30.0 \mathrm{~kg} / \mathrm{m}^{2}$.

$\ddagger$ Abdominal obesity was defined as waist circumference $\geq 88 \mathrm{~cm}$ for women or $\geq 102 \mathrm{~cm}$ for men.

$\S$ Depression was defined by the Center for Epidemiologic Studies Depression Scale (CES-D), twenty-item version: depressed participants defined by CES-D score $\geq 16$. This criterion has been previously used to define depressive symptoms in the adult Mexican population ${ }^{(22)}$.

those with normal waist circumference $(<88 \mathrm{~cm}$ for women and $<102 \mathrm{~cm}$ for men) at baseline were considered ( $n$ 470). To estimate the longitudinal effect of the MHQ on anthropometric outcomes (gaining $\geq 5 \%$ of body weight, becoming overweight/obese and developing abdominal obesity), Cochran's $Q$ tests were performed to assess changes in proportions of anthropometric indicators according to MHQ categories at baseline and after 7 years of follow-up (Table 5).
For both stages, generalized linear models with a loglink and binomial distribution were performed in order to obtain adjusted relative risks of weight gain, becoming overweight/obese and developing abdominal obesity according to the MHQ categories (Table 6) ${ }^{(45)}$. We used generalized linear models because it is a more accurate method when the outcome event is common (incidence of $10 \%$ or more $)^{(46,47)}$. Analyses were performed using the Stata statistical software package version 12.0.

\section{Results}

The study population was composed of mainly middleaged participants ( 44.5 years old at baseline and 52.6 years at follow-up); most participants were women (75\%), married or living in free union $(64.8 \%$ at baseline and $60.6 \%$ in the follow-up) and had a bachelor's degree or higher (48.2\% at baseline and $48.7 \%$ in follow-up assessment). Some the participants' other lifestyle and anthropometric characteristics changed after the study period: MHQ scores decreased from 5.3 to 4.8 points; the percentage of overweight and obesity increased from 57.2 to $64.6 \%$; abdominal obesity increased from 21.3 to $31.5 \%$ in men and from 50.0 to $63.5 \%$ in women; the percentage of recreational physically active participants decreased from $37 \cdot 1$ to $31.6 \%$; and the percentage of current smokers decreased from 15.8 to $11.3 \%$. The prevalence of participants who were categorized as depressed was similar at both times of assessment (21.0 and 20.0\%, respectively; Table 2).

Based on the baseline and follow-up MHQ scores a panel data set was obtained, then individuals were classified into tertiles in order to relate their MHQ status to their corresponding obesity status and weight gain from baseline to follow-up. Table 3 reports the relationship between sociodemographic, anthropometric and lifestyle characteristics and the MHQ categories, considering both assessments in the longitudinal panel data. Participants in the higher MHQ category were older than those in the lower MHQ group (mean age: $47.5 v .46 .0$ years, respectively; $P=0.000$ ) and a greater proportion of participants with a high school level education were in the lower MHQ category (26.2\%) than in the higher MHQ group (19.6\%; $P=0.040)$. Participants in the lower MHQ category had a greater body weight (66.3 v. $61.1 \mathrm{~kg}$, respectively; $P=0.000$ ), a higher proportion of overweight ( 44.9 v. $37.4 \%$, respectively; $P=0.010$ ) and obesity (24.5 v. $12.8 \%$, respectively; $P=0.000)$ and a greater percentage of abdominal obesity $(54.7 v .40 \cdot 6 \%$, respectively; $P=0.000)$ than those in the higher MHQ group. Regarding lifestyle characteristics, participants in the higher MHQ category were more likely to be physically active (37.7 v. $26 \cdot 7 \%$, respectively; $P=0.000$ ) and had a lower prevalence of depression ( $16 \cdot 8 v .26 \cdot 3 \%$, respectively; $P=0.000)$ than participants classified in the lower MHQ group.

Table 4 presents the participants' adherence to each of the three dietary patterns and their relationship with the 
Table 3 Demographic, anthropometric and lifestyle characteristics of the Mexican adult participants* across categories of the Mealtime Habits Quality (MHQ) score at baseline (2004-2006) and follow-up (2010-2012) evaluations; Health Workers Cohort Study, Morelos, Mexico

\begin{tabular}{|c|c|c|c|c|}
\hline & \multicolumn{4}{|c|}{ MHQ category $\dagger$} \\
\hline & Low ( $n$ 559) & Middle ( $n$ 557) & High ( $n 558)$ & $P$ value $\neq$ \\
\hline \multicolumn{5}{|l|}{ Demographic characteristics } \\
\hline Men $(\%)$ & $71 \cdot 7$ & $76 \cdot 3$ & $77 \cdot 0$ & 0.080 \\
\hline Age (years) & $46 \cdot 0$ & $50 \cdot 1$ & 47.5 & 0.000 \\
\hline \multicolumn{5}{|l|}{ Education } \\
\hline Elementary and secondary education (\%) & $25 \cdot 9$ & $32 \cdot 8$ & $30 \cdot 7$ & 0.060 \\
\hline High school (\%) & $26 \cdot 2$ & $20 \cdot 8$ & $19 \cdot 6$ & 0.040 \\
\hline Bachelor's degree or higher (\%) & 47.9 & $46 \cdot 4$ & 49.7 & 0.570 \\
\hline \multicolumn{5}{|l|}{ Marital status } \\
\hline Married or living in free union (\%) & $66 \cdot 4$ & $62 \cdot 4$ & $59 \cdot 4$ & 0.040 \\
\hline Divorced, widowed or separated (\%) & 33.6 & 37.5 & $39 \cdot 6$ & 0.110 \\
\hline \multicolumn{5}{|l|}{ Anthropometric variables } \\
\hline Weight $(\mathrm{kg})$ & $66 \cdot 3$ & $63 \cdot 8$ & $61 \cdot 1$ & 0.000 \\
\hline \multicolumn{5}{|l|}{ Waist circumference $(\mathrm{cm})$} \\
\hline Men & $98 \cdot 3$ & $96 \cdot 0$ & $93 \cdot 6$ & 0.000 \\
\hline Women & $92 \cdot 1$ & 91.0 & 88.0 & 0.000 \\
\hline $\operatorname{BMl}\left(\mathrm{kg} / \mathrm{m}^{2}\right)$ & $26 \cdot 9$ & $27 \cdot 1$ & $25 \cdot 4$ & 0.000 \\
\hline Normal weight§ (\%) & $30 \cdot 6$ & $36 \cdot 8$ & 49.8 & 0.000 \\
\hline Overweight§ (\%) & 44.9 & 44.8 & 37.4 & 0.010 \\
\hline Obesity§ (\%) & 24.5 & $18 \cdot 2$ & $12 \cdot 8$ & 0.000 \\
\hline Abdominal obesityll (\%) & $54 \cdot 7$ & $52 \cdot 0$ & $40 \cdot 6$ & 0.000 \\
\hline \multicolumn{5}{|l|}{ Lifestyle characteristics } \\
\hline \multicolumn{5}{|l|}{ Recreational physical activity } \\
\hline Active $\geq 30 \mathrm{~min} / \mathrm{d}(\%)$ & $26 \cdot 7$ & $38 \cdot 8$ & $37 \cdot 7$ & 0.000 \\
\hline Depression $1(\%)$ & $26 \cdot 3$ & 18.4 & $16 \cdot 8$ & 0.000 \\
\hline Current smoker (\%) & $13 \cdot 7$ & 11.2 & $15 \cdot 9$ & 0.070 \\
\hline
\end{tabular}

${ }^{*}$ For the longitudinal analysis, repeated measures were included in the panel data. Thus, the number of participants was 837 , while the number of observations was 1674.

†MHQ score was created by summing the factor loadings of each mealtime habits item. Each participant received an individual MHQ score at baseline and another at the follow-up assessment. The $\mathrm{MHQ}$ categories were defined as: lower $\mathrm{MHQ}$ category (score $=0$ to 4.27 points); middle $\mathrm{MHQ}$ category (score $=4.28$ to 5.70 points); and higher $\mathrm{MHQ}$ category (score $=5.71$ to 8.08 points).

$\ddagger P$ value calculated using Cochran's $Q$ test to assess differences in three proportions, and Fisher's test from linear regression to assess differences in three means, among low-, middle- and high-quality mealtime habits. Proportions and means were adjusted for age and sex. $P \leq 0.05$ was considered as significant. $\S$ Normal weight, $\mathrm{BMI}=18.5-24.9 \mathrm{~kg} / \mathrm{m}^{2}$; overweight, $\mathrm{BMI}=25.0-29.9 \mathrm{~kg} / \mathrm{m}^{2}$; obesity, $\mathrm{BMI} \geq 30.0 \mathrm{~kg} / \mathrm{m}^{2}$.

IIAbdominal obesity was defined as waist circumference $\geq 88 \mathrm{~cm}$ for women or $\geq 102 \mathrm{~cm}$ for men.

ITo determine which participants had depressive symptoms at baseline and follow-up, a twenty-item version of a self-administered questionnaire created by the Center for Epidemiologic Studies (CES-D) was used, which has been validated in Spanish-speaking groups and in this study population ${ }^{(22)}$.

MHQ categories, considering both assessments in the longitudinal panel data. A higher percentage of participants with greater adherence to the prudent dietary pattern were classified into the higher MHQ category than in the lower MHQ (39.2 v. 27.1\%, respectively; $P=0.002)$. A greater proportion of participants who followed the Western dietary pattern were grouped into the lower MHQ than the higher MHQ category (38.9 v. 26.7\%, respectively; $P=0 \cdot 000)$. Finally, more participants with lower adherence to the high protein/fat dietary pattern were classified into the higher MHQ than the lower MHQ category ( $41 \cdot 1 v \cdot 27 \cdot 0 \%$, respectively; $P=0 \cdot 000)$.

Table 5 shows that individuals classified in the lower MHQ category developed significantly worse anthropometric indicators over time, compared with those in the higher MHQ category. A significantly higher percentage of participants in the lower MHQ group gained $\geq 5 \%$ of weight (34.2 v. 5.6\%, respectively), became overweight/ obese (24.6 v. $2 \cdot 8 \%$, respectively) or developed abdominal obesity ( $25.0 v .3 .9 \%$, respectively) than in the higher MHQ group ( $P=0.000$ for all). These trends regarding gaining weight and becoming overweight/obese were similar for men and women; however, the percentage of men who developed abdominal obesity over time was not significantly different across MHQ categories.

Table 6 indicates the likelihood of gaining body weight, becoming overweight/obese or developing abdominal obesity across the three MHQ categories, after 7 years of follow-up. Participants in the middle and lower MHQ groups (compared with the higher MHQ category) showed a $4 \cdot 1$ and $6 \cdot 2$ times greater risk of gaining $\geq 5 \%$ of body weight, respectively (both $P=0 \cdot 000$ ). Participants in the middle and lower MHQ groups also had an increased risk of being overweight/obese of 6.6- and 8.6-fold, respectively (both $P=0 \cdot 000$ ), as well as a $3 \cdot 8$ - and $5 \cdot 3$-fold higher risk of developing abdominal obesity, respectively (both $P=0 \cdot 000$ ). Among women, the association between MHQ and the anthropometric indicators we evaluated was similar to what we observed with the total study population $(P=0.000$ in all cases). Men who were categorized in the middle and lower MHQ had a 7.5- and 12.6-fold greater risk of gaining weight than those in the higher MHQ category $(P=0.007$ and $P=0.000$, respectively) and men in the lower MHQ presented a $5 \cdot 0$-fold greater risk of 
Table 4 Dietary patterns adherence of the Mexican adult participants* across categories of the Mealtime Habits Quality (MHQ) score at baseline (2004-2006) and follow-up (2010-2012) evaluations; Health Workers Cohort Study, Morelos, Mexico

\begin{tabular}{|c|c|c|c|c|}
\hline & \multicolumn{4}{|c|}{ MHQ category $\dagger$} \\
\hline & Low $(n 521)$ & Middle ( $n$ 517) & High (n 502) & $P$ value $\ddagger$ \\
\hline Dietary patterns scoreł & $3 \cdot 4$ & 4.9 & $6 \cdot 2$ & 0.000 \\
\hline $\mathrm{SD}$ & 0.65 & 0.40 & 0.49 & \\
\hline \multicolumn{5}{|l|}{ Prudent dietary pattern } \\
\hline Tertile $1(\%)$ & $37 \cdot 2$ & $32 \cdot 3$ & 30.5 & 0.060 \\
\hline Tertile 2 (\%) & 35.5 & 34.7 & $29 \cdot 8$ & 0.102 \\
\hline Tertile $3(\%)$ & $27 \cdot 2$ & 33.0 & $39 \cdot 8$ & 0.000 \\
\hline \multicolumn{5}{|l|}{ Western dietary pattern } \\
\hline Tertile $1(\%)$ & $29 \cdot 3$ & 33.4 & $37 \cdot 3$ & 0.023 \\
\hline Tertile 2 (\%) & $30 \cdot 5$ & $34 \cdot 0$ & 35.5 & 0.221 \\
\hline Tertile 3 (\%) & $40 \cdot 2$ & $32 \cdot 6$ & $27 \cdot 2$ & 0.000 \\
\hline \multicolumn{5}{|c|}{ High protein/fat dietary pattern } \\
\hline Tertile $1(\%)$ & $26 \cdot 7$ & $32 \cdot 2$ & $41 \cdot 1$ & 0.000 \\
\hline Tertile 2 (\%) & $37 \cdot 7$ & $34 \cdot 1$ & $28 \cdot 2$ & 0.004 \\
\hline Tertile 3 (\%) & $35 \cdot 6$ & 33.7 & 30.7 & 0.254 \\
\hline
\end{tabular}

${ }^{*}$ For the longitudinal analysis, repeated measures were included in the panel data. Thus, the number of participants was 770 , while the number of observations was 1540 .

†MHQ score was created by summing the factor loadings of each mealtime habits item. Each participant received an individual MHQ score at baseline and another at the follow-up assessment. The MHQ categories were defined as: lower MHQ category (score $=0$ to 4.27 points); middle $\mathrm{MHQ}$ category (score $=4 \cdot 28$ to 5.70 points); and higher $\mathrm{MHQ}$ category (score $=5.71$ to 8.08 points)

$\ddagger P$ value calculated using Cochran's $Q$ test to assess differences in three proportions, and Fisher's test from linear regression to assess differences in three means, among low-, middle- and high-quality mealtime habits. Proportions and means were adjusted for age and sex. $P \leq 0.05$ was considered as significant. ‡Dietary patterns: prudent dietary pattern is typified by greater intakes of processed vegetable juices, potatoes, fresh fruits, fresh vegetables and legumes, and a lower intake of pastries; Western dietary pattern is typified by higher intakes of pastries, refined cereals, corn tortillas and soft drinks, and lower intakes of whole cereals, seafood and full-fat dairy products; and high protein/fat dietary pattern is typified by greater intakes of red meat, processed meat, margarine and eggs, and lower intakes of fruits and wholegrain cereals. Tertile 3 (T3) of each pattern represents greater adherence to the dietary pattern.

developing abdominal obesity than those in the higher MHQ category $(P=0 \cdot 027)$.

\section{Discussion}

The present prospective study provides evidence about the influence of a set of habitual mealtime behaviours on anthropometric indicators. Our findings support the hypothesis that participants who engage in unadvisable mealtime habits have an increased risk of developing an unhealthy body weight and anthropometric profile. Considering both assessments, individuals in the middle and low MHQ categories had a significantly higher likelihood of gaining weight, becoming overweight/obese and developing abdominal obesity after 7 years of follow-up than those in the high MHQ category.

The meal is the focus of nutrition research because most food is consumed as part of a meal, making it an appropriate context for addressing concerns about food intake $^{(48)}$. Our findings also support the hypothesis that usual mealtime habits can influence food intake and anthropometric measures, which is key to understanding how some mealtime circumstances may lead to high energy intake and consequently the development of unhealthy anthropometric indicators. In the present study, MHQ categories were associated with three dietary patterns: the healthiest MHQ category was linked to a prudent diet, while the unhealthiest MHQ category was related to a Western diet. A previous study of 7472
Mexican adults also showed that participants who were in the healthiest MHQ category reported a greater adherence to a prudent dietary pattern than to a Western one ${ }^{(21)}$.

In our study we analysed prospectively four mealtime items that are related to the availability of time to eat: taking time to eat, rushing meals, skipping meals and eating in large mouthfuls. Previous studies have shown that scarcity of time when eating might lead to rushing meals, eating out instead of at home and skipping meals, which are all linked to an increased consumption of fast foods and fewer home cooked meals ${ }^{(13,49)}$. Skipping meals and rushing meals can lead to decreased feelings of satiety at meal completion and are both linked to being overweight ${ }^{(50-52)}$. Rushing meals has been associated with higher intakes of soft drinks, fast foods and fat, a lower intake of healthy foods ${ }^{(13)}$ and a greater energy intake ${ }^{(51)}$. Other studies report that eating quickly is positively associated with a higher BMI, independent of total energy intake $^{(51,53)}$. Their findings suggest that energy intake is lower when a meal is eaten slowly, and satiety is higher at meal completion ${ }^{(50)}$.

We also examined activities that distract from eating, with the following items: distracted watching TV or reading, and distracted taking advantage of mealtime to accomplish work activities. Watching TV impairs one's ability to keep track of food consumption, which may lead to higher energy and fat intakes, thus increasing the likelihood of becoming overweight ${ }^{(9,10)}$. Watching TV is also associated with lower fruit and vegetable consumption ${ }^{(8,9)}$. There is evidence that TV watching can impact subsequent 
Table 5 Change in anthropometric indicators of the Mexican adult participants* across categories of the Mealtime Habits Quality (MHQ) score after 7 years of follow-up; Health Workers Cohort Study, Morelos, Mexico

\begin{tabular}{|c|c|c|c|c|}
\hline \multirow[b]{2}{*}{ Anthropometric indicator } & \multicolumn{4}{|c|}{ MHQ category† } \\
\hline & Low & Middle & High & $P$ value $\neq$ \\
\hline \multicolumn{5}{|l|}{ Gained body weight§ } \\
\hline Total (\%) & $34 \cdot 2$ & $22 \cdot 2$ & $5 \cdot 6$ & 0.000 \\
\hline Men (\%) & 31.8 & $18 \cdot \overline{8}$ & $2 \cdot 7$ & 0.000 \\
\hline Women (\%) & 34.8 & $23 \cdot 6$ & $6 \cdot 3$ & 0.000 \\
\hline \multicolumn{5}{|l|}{ Maintained body weight } \\
\hline Total (\%) & $65 \cdot 8$ & $77 \cdot 8$ & 94.4 & 0.000 \\
\hline Men (\%) & $68 \cdot 2$ & $81 \cdot 2$ & $97 \cdot 3$ & 0.000 \\
\hline Women (\%) & 65.2 & $76 . \overline{4}$ & 93.6 & 0.000 \\
\hline Total observations $=1414(\operatorname{men}=362$, women $=1052)$ & 476 & 470 & 468 & \\
\hline \multicolumn{5}{|l|}{ Became overweight/obesell } \\
\hline Total (\%) & 24.6 & $18 \cdot 2$ & $2 \cdot 8$ & 0.000 \\
\hline Men (\%) & $27 \cdot 8$ & $12 \cdot 3$ & 0.0 & 0.000 \\
\hline Women (\%) & 23.4 & 18.9 & 3.4 & 0.000 \\
\hline \multicolumn{5}{|l|}{ Maintained normal BMI } \\
\hline Total $(\%)$ & $75 \cdot 4$ & $81 \cdot 8$ & $97 \cdot 2$ & 0.000 \\
\hline Men (\%) & $72 \cdot 2$ & $87 \cdot 6$ & 0.0 & 0.000 \\
\hline Women $(\%)$ & $76 \cdot 6$ & $81 \cdot 1$ & $96 \cdot 6$ & 0.000 \\
\hline Total observations $=716(\operatorname{men}=148$, women $=568)$ & 204 & 230 & 282 & \\
\hline \multicolumn{5}{|l|}{ Developed abdominal obesity } \\
\hline Total & $25 \cdot 0$ & 19.9 & 3.9 & 0.000 \\
\hline Men (\%) & 4.4 & 0.0 & 0.0 & 0.092 \\
\hline Women $(\%)$ & $14 \cdot 9$ & $9 \cdot 2$ & $2 \cdot 2$ & 0.000 \\
\hline \multicolumn{5}{|l|}{ Maintained normal waist circumference } \\
\hline Total (\%) & $75 \cdot 0$ & $80 \cdot 1$ & $96 \cdot 1$ & 0.000 \\
\hline Men $(\%)$ & $95 \cdot 6$ & 0.0 & 0.0 & 0.092 \\
\hline Women (\%) & $85 \cdot 1$ & $90 \cdot 8$ & $97 \cdot 8$ & 0.000 \\
\hline Total observations $=600(\operatorname{men}=146$, women $=454)$ & 179 & 191 & 230 & \\
\hline
\end{tabular}

${ }^{*}$ For the longitudinal analysis, repeated measures were included in the panel data. Thus, the number of participants was 707 , while the number of observations was 1414.

TMHQ score was created by summing the factor loadings of each mealtime habits item. Each participant received an individual MHQ score at baseline and another at the follow-up assessment. The MHQ categories were defined as: lower MHQ category (score $=0$ to 4.27 points); middle $\mathrm{MHQ}$ category (score $=4.28$ to 5.70 points); and higher MHQ category (score $=5.71$ to 8.08 points).

$\ddagger P$ values were calculated using Cochran's $Q$ test to assess the differences in three proportions adjusted for sex and age.

$\S$ Gained body weight was defined as an increase of $\geq 5 \%$ in body weight after follow-up period. For this analysis, 130 participants who lost $\geq 5 \%$ of their body weight were excluded.

IBecame overweight/obese was defined as having a normal BMI (18.5-24.9 kg/m²) at baseline, but having an overweight/obese BMI ( $\left.\geq 25.0 \mathrm{~kg} / \mathrm{m}^{2}\right)$ after the follow-up period. Only participants with normal BMI at baseline were included in this analysis.

IDeveloped abdominal obesity was defined as having a normal waist circumference at baseline, but having a waist circumference of $\geq 88 \mathrm{~cm}$ for women or $\geq 102 \mathrm{~cm}$ for men after the follow-up period. Only participants with normal waist circumferences at baseline were included in this analysis.

meals by reducing memories of the last meal consumed, increasing food intake in the next meal and increasing the likelihood of consuming snacks ${ }^{(4)}$. Habitual TV viewing can also influence body weight simply by increasing inactivity, decreasing metabolic rate and exposing the viewer to appetizing commercials. Sitting in front of the TV leads to transient and exaggerated elevations in blood glucose, fatty acids and $\mathrm{TAG}^{(5,8)}$. In fact, TV viewing and eating snacks have been jointly associated with the metabolic syndrome and its components by means of 'mindless eating', causing people to ignore feelings of fullness ${ }^{(5)}$. Many other distractors from eating have also been related to increased energy intake ${ }^{(2)}$, including listening to a detective story ${ }^{(54)}$, listening to music ${ }^{(55)}$, playing video games ${ }^{(3)}$ and engaging in other tasks ${ }^{(56)}$.

Environmental factors at mealtime and their influence on energy intake and anthropometric status were also investigated in the present research, through the following items: eating with friends, family or colleagues, and number of times per week that participants ate their main meal at home. Previous research shows that environmental factors such as atmospherics, social interactions and distractions are associated with food intake $(1,2,10,57,58)$. The potential stimulatory influence of different environmental factors can make people more vulnerable to hunger ${ }^{(1)}$. Eating with others has been shown to increase energy intake in some contexts. For example, the sensory stimulation from food and the number of persons present at the meal can critically influence meal size, regardless of hunger ${ }^{(2)}$; however, eating with family members has some potential benefits, because families frequently adopt healthy eating habits ${ }^{(58,59)}$. Other studies have shown that meals eaten with other people tend to be larger and longer in duration compared with meals eaten alone, regardless of the relationship with the eating companion ${ }^{(10)}$. These results were consistently independent of the time of day, with similar effects observed in morning, noontime and evening meals ${ }^{(20)}$. An experimental study was conducted with two groups of forty healthy adult women (divided by level of dietary restraint), who participated in five different meal 
Table 6 Relative risks (RR) and $95 \%$ confidence intervals* of change in anthropometric indicators in the Mexican adult participants† across categories of the Mealtime Habits Quality (MHQ) score after 7 years of follow-up; Health Workers Cohort Study, Morelos, Mexico

\begin{tabular}{|c|c|c|c|c|c|c|c|c|c|}
\hline \multirow[b]{2}{*}{ MHQ category $\ddagger$} & \multicolumn{3}{|c|}{ Risk of gaining body weight§ } & \multicolumn{3}{|c|}{ Risk of becoming overweight/obesell } & \multicolumn{3}{|c|}{ Risk of developing abdominal obesity } \\
\hline & $\mathrm{RR}$ & $95 \% \mathrm{Cl}$ & $P$ value & $\mathrm{RR}$ & $95 \% \mathrm{Cl}$ & $P$ value & $\mathrm{RR}$ & $95 \% \mathrm{Cl}$ & $P$ value \\
\hline \multicolumn{10}{|c|}{ High (reference category) } \\
\hline Total & & 1.00 & & & 1.00 & & & 1.00 & \\
\hline Men & & 1.00 & & & 1.00 & & & 1.00 & \\
\hline Women & & 1.00 & & & 1.00 & & & 1.00 & \\
\hline \multicolumn{10}{|l|}{ Middle } \\
\hline Total & $4 \cdot 1$ & $2 \cdot 5,6 \cdot 7$ & 0.000 & $6 \cdot 6$ & $2 \cdot 8,15 \cdot 5$ & 0.000 & $3 \cdot 8$ & $2 \cdot 0,7 \cdot 3$ & 0.000 \\
\hline Men (n 289) & 7.5 & $1 \cdot 7,32 \cdot 5$ & 0.007 & & - & & 1.6 & $0.3,8.5$ & 0.574 \\
\hline Women (n 778) & 3.7 & $2 \cdot 2,6 \cdot 2$ & 0.000 & $5 \cdot 6$ & $2 \cdot 4,13 \cdot 1$ & 0.000 & 4.4 & $2 \cdot 2,8 \cdot 7$ & 0.000 \\
\hline \multicolumn{10}{|l|}{ Low } \\
\hline Total & $6 \cdot 2$ & $3.9,9.7$ & 0.000 & $8 \cdot 6$ & $3 \cdot 7,19 \cdot 8$ & 0.000 & $5 \cdot 3$ & $2 \cdot 8,9 \cdot 8$ & 0.000 \\
\hline Men ( $n$ 289) & $12 \cdot 6$ & $3 \cdot 1,51 \cdot 2$ & 0.000 & & - & & 5.0 & $1 \cdot 2,21 \cdot 2$ & 0.027 \\
\hline Women $(n 778)$ & 5.4 & $3 \cdot 3,8 \cdot 8$ & 0.000 & $6 \cdot 9$ & $2.9,16 \cdot 4$ & 0.000 & $5 \cdot 1$ & $2 \cdot 6,10 \cdot 0$ & 0.000 \\
\hline
\end{tabular}

${ }^{*} \mathrm{RR}$ and their $95 \% \mathrm{Cl}$ were calculated by means of generalized linear models, which were adjusted for sex, dietary patterns, depression, recreational physical activity and level education as categorical variables, and age and energy intake as continuous variables.

†For the longitudinal analysis, repeated measures were included in the panel data. Thus the number of participants was 534 , while the number of observations of 1068.

¥MHQ score was created by summing the factor loadings of each mealtime habits item. Each participant received an individual MHQ-score at baseline and another at the follow-up assessment. The MHQ categories were defined as: lower MHQ category (score $=0$ to 4.27 points); middle $\mathrm{MHQ}$ category (score $=4.28$ to 5.70 points); and higher MHQ category (score $=5.71$ to 8.08 points).

$\S$ Gaining weight was defined as an increase of $\geq 5 \%$ in body weight after the follow-up period. For this analysis 130 participants who lost $\geq 5 \%$ of body weight were excluded.

IBecoming overweight/obese was defined as having a normal BMI (18.5-24.9 kg/m²) at baseline, but having an overweight/obese BMI $\left(\geq 25.0 \mathrm{~kg} / \mathrm{m}^{2}\right)$ after the follow-up period. Only participants with normal BMI at baseline were included in this analysis.

IDeveloping abdominal obesity was defined as having normal waist circumference at baseline, but having a waist circumference of $\geq 88 \mathrm{~cm}$ in women and of $\geq 102 \mathrm{~cm}$ in men after the follow-up period. Only participants with normal waist circumferences at baseline were included in this analysis.

situations: eating alone, in a group, listening to a detective story, watching TV and watching advertisements on TV. Women with high levels of dietary restraint were more sensitive to external distractions present at mealtime and, contrary to expected, they ate less in groups than alone ${ }^{(19)}$.

Eating is an important part of culture, tradition and personal history; it is also a powerful expression of social identity $^{(60)}$. Familial and cultural eating habits were also explored in the current study through the following items: eating with family, friends or colleagues, eating at home, and eating everything on the plate. This last item is an unwritten social rule in many countries that generally shows appreciation for the food and sends a non-verbal message that the food was delicious. However, this custom has become an unhealthy habit because of the enormous serving sizes at restaurants ${ }^{(60,61)}$. In the familial context, large portions may contribute to overeating since relatives sometimes encourage children to finish their meal even if they are full, because it is interpreted as a sign of well-adjusted and healthy eating. Family rituals also dictate with whom, where and how long one eats, which seems to be the greatest driving factor of both adult and child $\mathrm{BMI}^{(60)}$. A study that examined the relationship between BMI and family dinner found that families who frequently ate dinner in the kitchen or in the dining room and remained at the table until everyone was finished eating had lower BMI for both parents and children, as compared with families who ate elsewhere ${ }^{(59)}$.

As part of our study, we also assessed food choices and the joy of eating with the following three items: choosing the type of food one eats thinking of one's health, choosing the amount of food one eats and enjoyment of eating. Food selection is an important intermediary factor to understand why people become overweight. What people choose to eat is influenced by individual, cultural and social values that can further empower consumers to make more conscious and informed choices ${ }^{(26)}$. People generally claim that taste is the most important factor in choosing what to eat, and foods high in sugar and fat are highly enjoyable and usually the most appealing to taste preferences, which triggers a desire to eat ${ }^{(61)}$. Contrarily, intuitive eating is highly related with balanced food intake and involves an ability to identify hunger sensations and satiety, allowing individuals to choose foods that are personally satisfying without any sense of deprivation. Intuitive eating has been associated with fewer food anxieties and less dieting behaviours, with greater pleasure associated with food, lower BMI, no negative aspect of diet composition, diet diversification and with eating breakfast ${ }^{(26)}$.

The present study has some weaknesses that should be addressed. We realize that the MHQ scale may be unable to capture all possible variations of mealtime behaviours, such as which meal of the day it is, the day of the week, specific eating contexts or the people present at particular meals. The items used in the study tended to generalize people's daily life experiences regarding meals, since the meal is the most important source of food intake ${ }^{(48)}$, and we sought to reflect a generally accurate picture of mealtime habits by identifying what people usually did at mealtimes. In addition, the MHQ scale was composed of binary response items at the baseline 
assessment that were changed to a multiple-choice response format in the follow-up assessment, which allowed us to explore a wider range of mealtime behaviours. An important strength of the study is that the MHQ scale is a comprehensive, reliable and valid measure due to its structure and ability to relate mealtime behaviours with dietary patterns and body weight status. Another major strength of the study is its longitudinal design, which can reveal changes in the MHQ score and in anthropometric measures more accurately than a cross-sectional design. This subject is relevant, due to anthropometric markers of obesity having been shown to significantly predispose people to metabolic diseases ${ }^{(35)}$, arterial stiffness, subclinical atherosclerosis ${ }^{(62)}$ and all-cause general mortality ${ }^{(63,64)}$. Finally, our findings are consistent with other studies in the Mexican population: a crosssectional study with 353 Mexican adolescents found that regular or better mealtime habits were associated with a 69 and $72 \%$ reduced risk of being overweight or obese, respectively ${ }^{(65)}$. Another cross-sectional study of Mexican health workers reported that poor mealtime habits were related to unhealthy dietary patterns and a higher $\mathrm{BMI}^{(21)}$.

The MHQ scale is a measure that brings together a set of different mealtime behaviours that people engage in simultaneously and attempts to represent a balance of unhealthy and healthy mealtime behaviours. Thus, the MHQ scale could be a useful population tool to predict long-term weight change because the meal is one of the most important sources of food intake and consequently weight status. Moreover, the associations found through the MHQ scale should be able to be replicated in other populations (such as children, adolescents and the elderly) to confirm the measure's ability to predict risk of developing certain metabolic disorders. This scale may also be useful for assessing the impact of health promotion interventions focused on mealtime habits, demonstrating how health education interventions that target mealtime behaviours can improve diet quality and reduce risk of weight gain.

\section{Acknowledgements}

Financial support: This study was funded by the Consejo Nacional de Ciencia y Tecnología (CONACyT; National Science and Technology Council) (grant numbers 7876 (year 2002) and 87783 (year 2008)) and supported by the HWCS. Y.N.F was supported by the National Cancer Institute (NCI)/National Institutes of Health (NIH) (grant number K07CA197179) for her work on this study. CONACyT, HWCS and NCI/NIH had no role in the design, analysis or writing of this article. Conflict of interest: The authors declare that they have no competing interests. Authorship: L.D.D.-C. and P.M.-H. were involved in the design of the study, statistical analysis and drafting the manuscript. C.S., B.R.-P. and K.G.-C. were involved in drafting the manuscript. E.D.-G., P.R. and E.S.-M. assisted with the statistical analysis and were involved in drafting the manuscript. Y.N.F. and J.S. contributed to the study design, coordination and to the original conception and design of the HWCS, and have given final approval of the manuscript to be published. All authors made critical comments during the preparation of the manuscript and fully accept responsibility for the work. Ethics of human subject participation: This research was conducted according to the guidelines laid down in the Declaration of Helsinki and all procedures involving human subjects were approved by the Ethics Committee of the Instituto Mexicano del Seguro Social (Mexican Social Security Institute) from the state of Morelos, Mexico. Written informed consent was obtained from all participants.

\section{Supplementary material}

To view supplementary material for this article, please visit http://dx.doi.org/10.1017/S1368980016002184

\section{References}

1. Wansink B (2004) Environmental factors that increase the food intake and consumption volume of unknowing consumers. Annu Rev Nutr 24, 455-579.

2. Bellisle F, Dalix AM \& Slama G (2004) Non food-related environmental stimuli induce increased meal intake in healthy women: comparison of television viewing versus listening to a recorded story in laboratory settings. Appetite 43, 175-180.

3. Ogden J, Coop N, Cousins C et al. (2013) Distraction, the desire to eat and food intake. Towards an expanded model of mindless eating. Appetite 62, 119-126.

4. Robinson E, Aveyard P, Daley A et al. (2013) Eating attentively: a systematic review and meta-analysis of the effect of food intake memory and awareness on eating. Am J Clin Nutr 97, 728-742.

5. Thorp AA, McNaughton SA, Owen N et al. (2013) Independent and joint associations of TV viewing time and snack food consumption with the metabolic syndrome and its components; a cross-sectional study in Australian adults. Int J Behav Nutr Phys Act 10, 96.

6. Long S, Meyer C, Leung N et al. (2011) Effects of distraction and focused attention on actual and perceived food intake in females with non-clinical eating psychopathology. Appetite 56, 350-356.

7. Higgs S \& Woodward M (2009) Television watching during lunch increases afternoon snack intake of young women. Appetite 52, 39-43.

8. Cleland VJ, Schmidt MD, Dwyer T et al. (2008) Television viewing and abdominal obesity in young adults: is the association mediated by food and beverage consumption during viewing time or reduced leisure-time physical activity? Am J Clin Nutr 87, 1148-1155.

9. Moray J, Fu A, Brill K et al. (2007) Viewing television while eating impairs the ability to accurately estimate total amount of food consumed. Bariatr Surg Pract Patient Care 2, 71-76

10. Hetherington MM, Anderson AS, Norton GN et al. (2006) Situational effects on meal intake: a comparison of eating alone and eating with others. Physiol Behav 88, 498-505.

11. Martínez-Díaz DJ (2009) Valores y creencias en el consumo de comidas en los hogares barraquilleros. Rev Cient Pensamiento Gestión issue 27; available at http://rcientificas. uninorte.edu.co/index.php/pensamiento/article/view/ $835 / 4954$ 
12. Raulio S, Roos E, Mukala K et al. (2008) Can working conditions explain differences in eating patterns during working hours? Public Health Nutr 11, 258-270.

13. Larson NI, Nelson MC, Neumark-Sztainer D et al. (2009) Making time for meals: meal structure and associations with dietary intake in young adults. J Am Diet Assoc 109, 72-79.

14. Smith KJ, Gall SL, McNaughton SA et al. (2010) Skipping breakfast: longitudinal associations with cardiometabolic risk factors in the Childhood Determinants of Adult Health Study. Am J Clin Nutr 92, 1316-1325.

15. Timlin MT \& Pereira MA (2007) Breakfast frequency and quality in the etiology of adult obesity and chronic diseases. Nutr Rev 65, 268-281.

16. Lachat C, Nago E, Verstraeten R et al. (2012) Eating out of home and its association with dietary intake: a systematic review of the evidence. Obes Rev 13, 329-346.

17. Crawford D, Ball K, Mishra G et al. (2007) Which foodrelated behaviors are associated with healthier intakes of fruits and vegetables among women? Public Health Nutr 10, 256-265.

18. Kruger J, Blanck HM \& Gillespie C (2008) Dietary practices, dining out behavior and physical activity correlates of weight loss maintenance. Prev Chronic Dis 5, A11.

19. Bellisle F, Dalix AM, Airinei G et al. (2009) Influence of dietary restraint and environmental factors on meal size in normalweight women. A laboratory study. Appetite 53, 309-313.

20. De Castro JM (1994) Family and friends produce greater social facilitation of food intake than other companions. Physiol Behav 56, 445-445.

21. Dosamantes-Carrasco D, Méndez-Hernández P, DenovaGutiérrez E et al. (2011) Scale for assessing the quality of Mexican adults' mealtime habits. Salud Publica Mex $\mathbf{5 3}$ 152-159.

22. Gallegos-Carrillo K, Flores YN, Denova-Gutiérrez E et al. (2013) Physical activity and reduced risk of depression: results of a longitudinal study of Mexican adults. Health Psychol 32, 609-615.

23. Council for International Organizations of Medical Sciences, World Health Organization (2002) International Ethical Guidelines for Biomedical Research Involving Human Subjects. Geneva: CIOMS.

24. Spector P (1992) Summated Rating Scale Construction: An Introduction. Sage University Paper Series on Quantitative Applications in the Social Sciences, no. 07-082. Newbury Park, CA: SAGE Publications, Inc.

25. Goon S \& Islam S (2014) Breakfast skipping and obesity risk among urban adults in Bangladesh. Int J Public Health Sci 3, $15-22$.

26. Smith $\mathrm{T} \&$ Hawks SR (2006) Intuitive eating, diet composition, and the meaning of food in healthy weight promotion. Am J Health Educ 37, 130-136.

27. DeVellis RF (2003) On building Likert scales. In Scale Development: Theory and Applications, pp. 3-7. Thousand Oaks, CA: SAGE Publications, Inc.

28. Mendez-Hernandez P, Dosamantes-Carrasco D, Siani C et al. (2012) A workplace physical activity program at a public university in Mexico can reduce medical costs associated with type 2 diabetes and hypertension. Salud Publica Mex 54, 20-27.

29. Méndez-Hernández P, Siani C, Lamure M et al. (2008) Préférences déclarées sur trois programs d'activité physique pour empêcher les maladies chroniques au Mexique. Proceedings of gème Conférence internationale sur la science des systèmes de santé. Nouvelles technologies de l'information et gouvernance des systèmes de santé, Lyon, France, 3-5 September, p. 188.

30. Hernández-Avila M, Romieu I, Parra S et al. (1998) Validity and reproducibility of a food frequency questionnaire to assess dietary intake of women living in Mexico City. Salud Publica Mex 40, 133-140.
31. Denova-Gutiérrez E, Castañón S, Talavera JO et al. (2010) Dietary patterns are associated with metabolic syndrome in an urban Mexican population. J Nutr 140, 1855-1863.

32. National Cholesterol Education Program, National Heart, Lung, and Blood Institute, National Institutes of Health (2001) Third Report of the National Cholesterol Education Program (NCEP) Expert Panel on Detection, Evaluation and Treatment of High Blood Cholesterol in Adults (Adult Treatment Panel III); Executive Summary. NIH Publication no. 01-3670. Washington, DC: US Department of Health and Human Services.

33. World Health Organization (1995) Physical Status: The Use and Interpretation of Anthropometry. Report of a WHO Expert Committee. WHO Technical Report Series no. 854. Geneva: WHO.

34. Colditz GA, Willett WC, Rotnitzky A et al. (1995) Weight gain as a risk factor for clinical diabetes mellitus in women. Ann Intern Med 122, 481-486.

35. World Health Organization (2003) Diet, Nutrition and the Prevention of Chronic Diseases. Report of a Joint WHO/FAO Expert Consultation. WHO Technical Report Series no. 916. Geneva: WHO

36. Katzmarzyk PT, Mire E, Bray GA et al. (2013) Anthropometric markers of obesity and mortality in white and African American adults: the Pennington center longitudinal study. Obesity (Silver Spring) 21, 1070-1075.

37. Maru S, Van Der Schouw YT, Gimbrère CHF et al. (2004) Body mass index and short-term weight change in relation to mortality in Dutch women after age 50 y. Am J Clin Nutr 80, 231-236.

38. Radloff LS (1977) The CES-D scale: a self-report depression scale for research in the general population. Appl Psychol Meas 1, 385-401.

39. Wolf AM, Hunter DJ, Colditz GA et al. (1994) Reproducibility and validity of a self-administered physical activity questionnaire. Int J Epidemiol 23, 991-999.

40. Martínez-González MA, López-Fontana C, Varo JJ et al. (2005) Validation of the Spanish version of the physical activity questionnaire used in the Nurses' Health Study and the Health Professionals' Follow-up Study. Public Health Nutr 8, 920-927.

41. Méndez-Hernández P, Flores Y, Siani C et al. (2009) Physical activity and risk of metabolic syndrome in an urban Mexican cohort. BMC Public Health 9, 276.

42. Fernández-García V \& Hernández-Tezoquipa I (2007) Promoción de la actividad Física. Cuernavaca, México: Instituto Nacional de Salud Pública, Secretaría de Salud.

43. World Health Organization (1997) Tobacco or Health: A Global Status Report. Geneva: WHO.

44. Baltagi BH (2004) Panel Data Theory and Applications. Series: Studies in Empirical Economics. Berlin/Heidelberg: Springer-Verlag GmbH \& Co. KG.

45. Twisk JW (2003) Applied Longitudinal Data Analysis. A Practical Guide. Cambrige, MA: Cambridge University Press.

46. Greenland S (2004) Model-based estimation of relative risks and other epidemiologic measures in studies of common outcomes and in case-control studies. Am J Epidemiol 160, 301-305.

47. McNutt LA, Wu C \& Xue X (2003) Estimating the relative risk in cohort studies and clinical trials of common outcomes. Am J Epidemiol 157, 940-943.

48. Meiselman HL (2009) Meals in Science and Practice: Interdisciplinary Research and Business Applications. Woodhead Publishing Series in Food Science, Technology and Nutrition, no. 171. Boca Raton, FL: CRC Press LLC.

49. Larson NI, Perry CL, Story M et al. (2006) Food preparation by young adults is associated with better diet quality. $J \mathrm{Am}$ Diet Assoc 106, 2001-2007. 
50. Andrade AM, Green GW \& Melanson KJ (2008) Eating slowly led to decreases in energy intake within meals in healthy women. J Am Diet Assoc 108, 1186-1191.

51. Maruyama K, Sato S, Ohira T et al. (2008) The joint impact on being overweight of self reported behaviours of eating quickly and eating until full: cross sectional survey. BMJ 337, a2002.

52. Kimura Y, Nanri A, Matsushita Y et al. (2011) Eating behavior in relation to prevalence of overweight among Japanese men. Asia Pac J Clin Nutr 20, 29-34.

53. Kamath S \& D'Souza J (2013) Prevalence of obesity among the medical students: a cross sectional study in a south Indian medical college. Al Ameen J Med Sci 6, 93-95.

54. Bellisle F \& Dalix A (2001) Cognitive restraint can be offset by distraction, leading to increased meal intake in women. Am J Clin Nutr 74, 197-200.

55. Stroebele N \& De Castro JM (2006) Listening to music while eating is related to increases in people's food intake and meal duration. Appetite 47, 285-289.

56. Boon B, Stroebe W, Schut $\mathrm{H}$ et al. (2002) Ironic processes in the eating behaviour of restrained eaters. Br J Health Psychol 7, 1-10.

57. Boitelle KN, Birnbaum AS, Lytle LA et al. (2003) Associations between perceived family meal environment and parent intake of fruit, vegetables, and fat. J Nutr Educ Behav 35, 24-29.

58. Wansink B \& Van Kleef E (2013) Dinner rituals that correlate with child and adult BMI. Obesity (Silver Spring) 22, E91-E95.
59. Videon TM \& Manning CK (2003) Influences on adolescent eating patterns: the importance of family meals. $J$ Adolesc Health 32, 365-373.

60. Anderson EN (2014) Me, myself, and the others: food as a social marker Everyone Eats: Understanding Food and Culture, 2nd ed., pp. 171-187. New York: New York University Press.

61. Ouwehand C \& De Ridder DT (2008) Effects of temptation and weight on hedonics and motivation to eat in women. Obesity (Silver Spring) 16, 1788-1793.

62. Recio-Rodriguez JI, Gomez-Marcos MA, Patino-Alonso MC et al. (2012) Abdominal obesity vs general obesity for identifying arterial stiffness, subclinical atherosclerosis and wave reflection in healthy, diabetics and hypertensive. $B M C$ Cardiovasc Disord 12, 3.

63. Boggs DA, Rosenberg L, Cozier YC et al. (2011) General and abdominal obesity and risk of death among black women. $N$ Engl J Med 365, 901-908.

64. Berrington de Gonzalez A, Hartge P, Cerhan JR et al. (2010) Body-mass index and mortality among 1.46 million white adults. $N$ Engl J Med 363, 2211-2219.

65. Pierlot R (2016) Estudio sobre la promoción de un estilo de vida saludable en jóvenes de bachillerato de Ixtenco, Tlaxcala, México (Research on the promotion of a healthy lifestyle in high schoolers from Ixtenco, Tlaxcala, México). PhD Thesis, Universidad Autónoma de Tlaxcala. 